\title{
sciforum
}

Conference Proceedings Paper

\section{Prediction of Annual Inflow to Karkheh Dam Reservoir using Time Series Models}

\author{
Karim Hamidi Machekposhti ${ }^{1}$, Hossein Sedghi ${ }^{2, *}$, Abdolrasoul Telvari ${ }^{3}$,Hossein Babazadeh 4 \\ Published: 05/11/2017 \\ Academic Editor: Sergio Vicente-Serrano \\ 1 Department of Water Sciences and Engineering, Islamic Azad University, Science and Research Branch, \\ Tehran, Iran; Email: karim.hamidi@srbiau.ac.ir \\ 2 Department of Water Sciences and Engineering, Science and Research Branch, Islamic Azad University, \\ Tehran, Iran; Email: h.sedghi1320@gmail.com \\ 2 Department of Civil Engineering, Islamic Azad University, Ahvaz, Iran; Email: telvari@gmail.com \\ 4 Department of Water Sciences and Engineering, Science and Research Branch, Islamic Azad University, \\ Tehran, Iran; Email: h_babazadeh@srbiau.ac.ir \\ * Correspondence: h.sedghi1320@gmail.com; Tel.: +98-912-348-6557
}

\begin{abstract}
The optimal exploitation of water from a dam reservoir requires a comprehensive knowledge of future availability of water resources. In this case the amount of water that will be available in the future is important. Also, we need to examine the flows at the dam from a shortterm perspective. This is necessary to avoid overflowing and to minimize damage. In order to facilitate forecasting of the water resources, many different techniques have been developed through the years. In this paper, using annual mean flow data (since 1958-2005) obtained from Jelogir Majin hydrometric station at Karkheh River (upstream of Karkheh dam), an Auto Regressive Integrated Moving Average (ARIMA) model, for prediction of annual mean inflow to Karkheh dam reservoir was accomplished. On the basic of comparison the results of the model with measured data, the performance of ARIMA $(4,1,1)$ model by Conditional Least Square (CLS) estimation parameter method is acceptable. The SAS and SPSS softwares were used to implement of the models.
\end{abstract}

Keywords: ARIMA, Reservoir, Time Series Model, Inflow Prediction, Karkheh Dam

\section{Introduction}

Increased need to water resources with proper quantity and quality besides possessing temporal and spatial distribution adapted with operation needs required engineers and investigators of water sources to make more efficient managerial systems for hydrosystems. It is needless telling that accuracy in predicting the streams of forthcoming periods has valuable effect on the efficiency of decision support systems for operating the reservoir. Prediction includes approximating the future situation of a parameter with 4 dimensions: quality, quantity, space and time [5]. Regarding to the statistics in Iran, it seems that time series models are acceptable variants for developing the flow prediction model. The basic theory for developing mentioned models is that the future is a reflection of past and any statistical relation that could be found in the historical statistics can be generalized to the future. The main development of time series models and their concepts resulting in vast application of these models, were conducted by Box and Jenkins (1970 \& 1976). The method used by these investigators was later called Box-Jenkins method and attracted the hydrologists. Musa (2013) studied flow discharge from the Shiroro river (since 1990-2011) by an Autoregressive Moving 
The 1st International Electronic Conference on Hydrological Cycle (CHyCle-2017), 12 -16 November 2017; Sciforum Electronic Conference Series, Vol. 1, 2017

Average model (ARMA) and analyzed with three different models namely; Autoregressive (AR), Autoregressive Moving Average (ARMA) and Autoregressive Integrated Moving Average (ARIMA) models. Based on the model analysis and evaluations, proper predictions for the effective usage of the flow from the river for farming activities and generation of power for both industrial and domestic us were made. It also highlights some recommendations to be made to utilize the possible potentials of the river effectively [4].

Shakeel et al. (1993) applied time series modelling of annual maximum flow of river Indus at Sukkur India. They find that ARIMA $(2,1,1)$ was appropriate for these series [5]. Srikanthan et al. (1983) used time series models to analize annual flow of Australian streams. Autocorrelation and partial autocorrelation functions were applied to determine the appropriate form of Box-Jenkins time series models [6]. Stojković et al. (2015) studied stochastic structure of annual discharges of large European rivers. They suggested that the stochastic flows simulated by the model can be used for hydrological simulations in river basins [7]. In another study, Vijayakumar and Vennila (2016) suggested that ARMA $(2,4)$ is the best model for generated annual inflow of Krishnagiri Reservoir in the state of Tamilnadu, India [8]. Hamidi Machekposhti et al. (2017) forecasted inflow of Karkheh dam at Iran by time series models and found that the ARIMA models are suitable for predicting of annual inflow series [2]. Adeli et al. (2015) used stochastic models to produce artificial time series and inflow prediction in Talog dam reservoir in Khuzestan province at Iran. The results of modelling showed that $\operatorname{ARMA}(2,3)$ was the best in comparison with the other models [1]. Similar research results indicate the ability and advantage of time series models to predict the flow of the river.

In this study, we used time series models such as ARMA and ARIMA models to predict Karkheh river flow at the entrance to Karkheh dam reservoir in Jelogir Majin hydrometric station.

\subsection{Case study}

Here we use a time series model for predicting the annual inflow to Karkheh dam reservoir. Karkheh dam is the largest dam construction in Iran. This is built on Karkheh river, the third largest river in Iran with 900 kilometer in length. It is in the Northwestern province of Khuzestan, the closest city being Andimeshk. It is 127 meter ( $417 \mathrm{ft}$ ) high and has a reservoir capacity of 5.9 billion cubic meter. This dam is located in geographic longitudinal and transversal $46^{\circ} 57^{\prime}-49^{\circ} 10^{\prime} \mathrm{E}$ and $31^{\circ} 48^{\prime}$ $34^{\circ} 56^{\prime} \mathrm{N}$, respectively. The reservor shows different uses:

i) To Control the devastating floods of Karkheh stream;

ii) To Regulate the water for irrigation usage and;

iii) To Provide required force for power supply.

Figure 1 shows the study area location. The average inflows to Karkheh dam from 1958 to 2005 in Jelogir Majin hydrometric station (upstream of Karkheh dam) are shown in Figure 2. Data was provided from Iran Water Resources Management Organization (IWRMO).

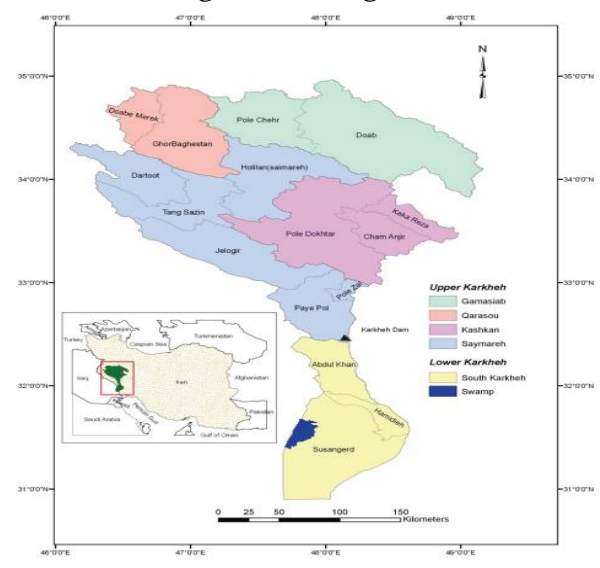

Figure 1. The study area location 
The 1st International Electronic Conference on Hydrological Cycle (CHyCle-2017), 12 -16 November 2017; Sciforum Electronic Conference Series, Vol. 1, 2017

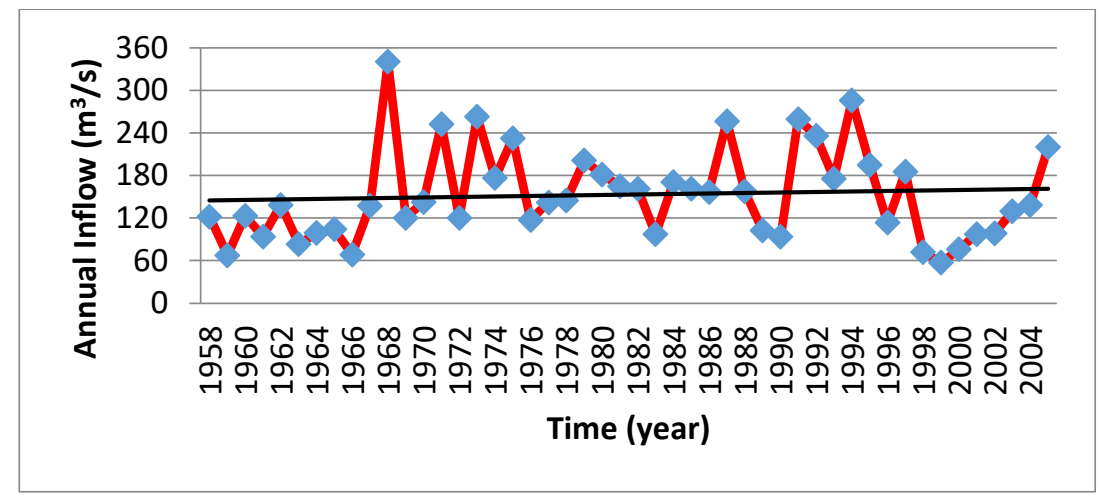

Figure 2. Time series for the annual inflow to Karkheh dam reservoir

\section{Methods}

Method of this study is conducted by time series analysis, one of these methods called ARIMA method or Box-Jenkins model or $(p, d, q)$ model. In any $(p, d, q)$ model, $p$ indicates the number of autoregressive, $\mathrm{q}$ is the number of mobile mean and $\mathrm{d}$ is the order of non-seasonal differencing as well as indicating the number of orders needed for attaining the series to a kind of statistical balance. In the first stage, the analysis of initial values of $\mathrm{p}, \mathrm{d}$ and $\mathrm{q}$ is determined by Auto Correlation Function (ACF) and Partial Auto Correlation Function (PACF). By accurately studying the ACF and PACF charts and their components, the general view for presence of time series with trend and their properties are obtained. Then in the second stage, it is examined if $p$ and $q$ values, indicating the autoregressive and mobile mean, remain in the model or must be removed from. In the third stage, it is reviewed whether the residual values, residual error are random and with normal distribution or not. In this case, one can say that this model enjoys proper fitness. A special type of non-seasonal models indicating the proper results and adapted to the general structure of ARIMA models according to Box-Jenkins (1976) called non-seasonal model. This model is ARIMA (p,d,q). Then for ideal model, it must be used models for testing the model and compared among them to select best model for prediction.

During time series analysis or generally in data analysis, it may be used several proper model for indicating a given data set. When applying the ARIMA model, the Akaike Information Criterion (AIC) has higher accuracy and it acts better comparing two ARIMA model for selecting the best fitting function. In this study there was used ARIMA and AIC test for modelling the inflow to reservoir and studying their effects on each other. According AIC test any model with minimum AIC value is suitable for prediction. After determining the type of model and its parameters as well as determining the proper AIC value, for validating the model, crop years 2006 to 2015 were considered as control and actual values were compared with predicted values.

\section{Results and Discussion}

Time series diagram for inflow to Karkheh dam reservoir indicated in Figure 2. ACF and PACF diagrams have drawn in Figure 3 to determine the initial model. The regular non-seasonal changes are indicated by these diagrams. The series are not static and show non-seasonal changes. 
The 1st International Electronic Conference on Hydrological Cycle (CHyCle-2017), 12 -16 November 2017; Sciforum Electronic Conference Series, Vol. 1, 2017

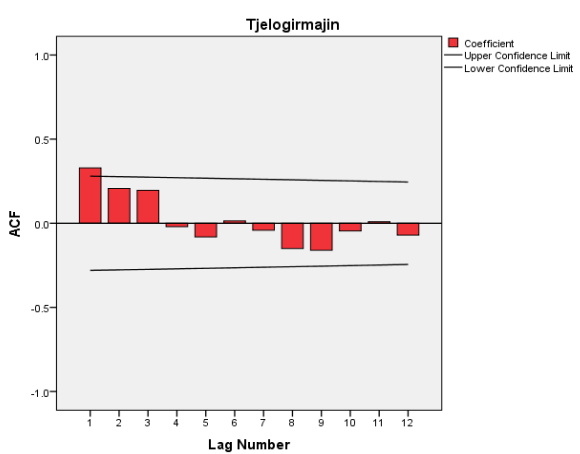

(a)

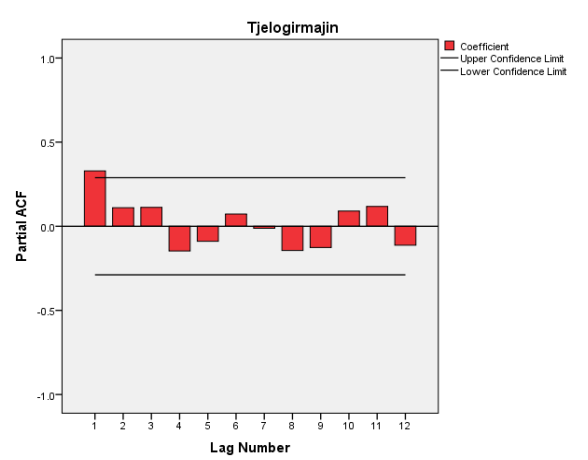

(b)

Figure 3. Diagram for (a) ACF and (b) PACF of time series of annual inflow to Karkheh dam reservoir

Consequently, the variability of time series will be increased over the time, therefore, data series is not static in variance and it could become static by Box-Cox method. The Maximum Likelihood (ML), Conditional Least Square (CLS) and Unconditional Least Square (ULS) methods are used to estimate the model parameters. The result of values for the parameters estimation of three selected models $(1,1,0),(1,1,1)$ and $(4,1,1)$ show in Table 1 . This table shows that all three models are suitable for modelling this data. Therefor we select the best model with Akaike Information Criterion (AIC). For verifying the model we used ACF and PACF diagram for residuals of inflow to dam reservoir in Figure 4 where the auto correlations were in the range of zero and the assumption for independency and stochastic data was accepted.

Also result of auto correlation check of residuals for data is given in Table 2. The goodness of fit statistic for this data is in Table 3. Finally, the best model for predicting the values of inflow to Karkheh dam reservoir is ARIMA $(4,1,1)$ which estimate by CLS method. Forecasting of annual mean flow from period 2006 to 2015 came in Table 4 and the correlation between actual values and predicted values indicated in Figures 5 and 6. 
The 1st International Electronic Conference on Hydrological Cycle (CHyCle-2017), 12 -16 November 2017;

Sciforum Electronic Conference Series, Vol. 1, 2017

Table 1. Result of parameter estimation for the selected models

\begin{tabular}{|c|c|c|c|c|c|c|c|}
\hline Parameter & $\begin{array}{c}\text { Estimation } \\
\text { Method }\end{array}$ & $\begin{array}{c}\text { Type (Order) and } \\
\text { Values of Parameters } \\
\text { ARIMA }(p, 1, q)\end{array}$ & $\begin{array}{l}\text { Std. } \\
\text { Error }\end{array}$ & $\begin{array}{l}\text { Absolute } \\
\text { Value of } t\end{array}$ & $\begin{array}{c}\text { Probability } \\
\text { of } \mathbf{t}\end{array}$ & $\begin{array}{l}\text { Stationary } \\
\text { Condition }\end{array}$ & $\begin{array}{c}\text { Invertibility } \\
\text { Condition }\end{array}$ \\
\hline \multirow{9}{*}{ 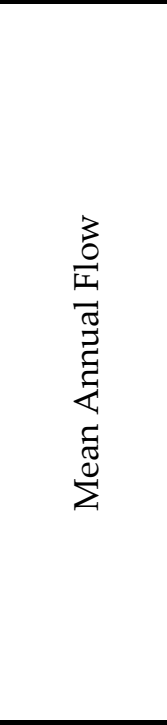 } & ML & $\begin{array}{c}\mathrm{p}(1)=-0.41932 \\
\mathrm{q}(0)\end{array}$ & 0.13457 & -3.12 & 0.0018 & Satisfy & \\
\hline & CLS & $\begin{array}{c}p(1)=-0.41473 \\
q(0)\end{array}$ & 0.13576 & -3.05 & 0.0037 & Satisfy & \\
\hline & ULS & $\begin{array}{c}\mathrm{p}(1)=-0.42872 \\
\mathrm{q}(0)\end{array}$ & 0.13480 & -3.18 & 0.0026 & Satisfy & \\
\hline & ML & $\begin{array}{l}\mathrm{p}(1)=0.36414 \\
\mathrm{q}(1)=0.99994\end{array}$ & $\begin{array}{c}0.15423 \\
52.247\end{array}$ & $\begin{array}{l}2.36 \\
0.02\end{array}$ & $\begin{array}{l}0.0182 \\
0.9847\end{array}$ & Satisfy & Not Satisfy \\
\hline & CLS & $\begin{array}{l}\mathrm{p}(1)=0.34486 \\
\mathrm{q}(1)=0.96630\end{array}$ & $\begin{array}{l}0.15246 \\
0.04271\end{array}$ & $\begin{array}{c}2.26 \\
22.62\end{array}$ & $\begin{array}{c}0.0286 \\
0.0001<\end{array}$ & Satisfy & Satisfy \\
\hline & ULS & $\begin{array}{l}\mathrm{p}(1)=0.35777 \\
\mathrm{q}(1)=0.99998\end{array}$ & $\begin{array}{l}0.14375 \\
0.29826 \\
\end{array}$ & $\begin{array}{l}2.49 \\
3.35 \\
\end{array}$ & $\begin{array}{l}0.0166 \\
0.0016 \\
\end{array}$ & Satisfy & Not Satisfy \\
\hline & ML & $\begin{array}{l}\mathrm{p}(4)=-0.1636 \\
\mathrm{q}(1)=0.66032\end{array}$ & $\begin{array}{l}0.15570 \\
0.12124\end{array}$ & $\begin{array}{l}-1.5 \\
5.45\end{array}$ & $\begin{array}{c}0.2933 \\
0.0001<\end{array}$ & Satisfy & Satisfy \\
\hline & CLS & $\begin{aligned} p(4) & =-0.17507 \\
q(1) & =0.68987\end{aligned}$ & $\begin{array}{l}0.15914 \\
0.11569\end{array}$ & $\begin{array}{l}-1.1 \\
5.96\end{array}$ & $\begin{array}{c}0.2771 \\
0.0001<\end{array}$ & Satisfy & Satisfy \\
\hline & ULS & $\begin{array}{l}\mathrm{p}(4)=-0.18146 \\
\mathrm{q}(1)=0.68935\end{array}$ & $\begin{array}{l}0.15870 \\
0.11617\end{array}$ & $\begin{array}{c}-1.14 \\
5.93\end{array}$ & $\begin{array}{c}0.2589 \\
0.0001<\end{array}$ & Satisfy & Satisfy \\
\hline
\end{tabular}

ML: Maximum Likelihood

CLS: Conditional Least Square

ULS: Unconditional Least Square

Table 2. Result of autocorrelation check of residuals

\begin{tabular}{|c|c|c|c|c|c|c|c|}
\hline Parameter & $\begin{array}{c}\text { ARIMA } \\
\text { Model }\end{array}$ & $\begin{array}{c}\text { Estimation } \\
\text { Method }\end{array}$ & $\begin{array}{l}\text { To } \\
\text { Lag }\end{array}$ & Df & Chi-Square & $\begin{array}{l}\text { Pr>Chi } \\
\text { Square }\end{array}$ & $\begin{array}{c}\text { Adequacy for } \\
\text { Modelling }\end{array}$ \\
\hline \multirow{28}{*}{ 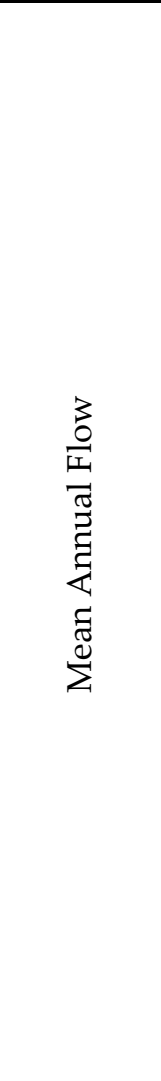 } & \multirow{12}{*}{$\operatorname{ARIMA}(1,1,0)$} & \multirow{4}{*}{ ML } & 6 & 5 & 8.04 & 0.1540 & \multirow{4}{*}{ Satisfy } \\
\hline & & & 12 & 11 & 11.80 & 0.3792 & \\
\hline & & & 18 & 17 & 17.84 & 0.3990 & \\
\hline & & & 24 & 23 & 26.29 & 0.2875 & \\
\hline & & \multirow{4}{*}{ CLS } & 6 & 5 & 7.87 & 0.1636 & \multirow{4}{*}{ Satisfy } \\
\hline & & & 12 & 11 & 11.83 & 0.3764 & \\
\hline & & & 18 & 17 & 17.88 & 0.3963 & \\
\hline & & & 24 & 23 & 26.24 & 0.2898 & \\
\hline & & \multirow{4}{*}{ ULS } & 6 & 5 & 8.08 & 0.1517 & \multirow{4}{*}{ Satisfy } \\
\hline & & & 12 & 11 & 11.87 & 0.3733 & \\
\hline & & & 18 & 17 & 17.97 & 0.3906 & \\
\hline & & & 24 & 23 & 26.52 & 0.2771 & \\
\hline & \multirow{4}{*}{$\operatorname{ARIMA}(1,1,1)$} & \multirow{4}{*}{ CLS } & 6 & 4 & 3.17 & 0.5296 & \multirow{4}{*}{ Satisfy } \\
\hline & & & 12 & 10 & 4.99 & 0.8920 & \\
\hline & & & 18 & 16 & 8.33 & 0.9386 & \\
\hline & & & 24 & 22 & 11.96 & 0.9583 & \\
\hline & \multirow{12}{*}{$\operatorname{ARIMA}(4,1,1)$} & \multirow{4}{*}{ ML } & 6 & 4 & 2.98 & 0.5618 & \multirow{4}{*}{ Satisfy } \\
\hline & & & 12 & 10 & 6.31 & 0.7883 & \\
\hline & & & 18 & 16 & 11.02 & 0.8082 & \\
\hline & & & 24 & 22 & 16.88 & 0.7699 & \\
\hline & & & 6 & 4 & 3.1 & 0.5416 & \multirow{4}{*}{ Satisfy } \\
\hline & & $C I \mathrm{C}$ & 12 & 10 & 7.19 & 0.7074 & \\
\hline & & CLS & 18 & 16 & 11.74 & 0.7617 & \\
\hline & & & 24 & 22 & 17.32 & 0.7455 & \\
\hline & & \multirow{4}{*}{ ULS } & 6 & 4 & 3.01 & 0.557 & \multirow{4}{*}{ Satisfy } \\
\hline & & & 12 & 10 & 6.34 & 0.7858 & \\
\hline & & & 18 & 16 & 10.94 & 0.8134 & \\
\hline & & & 24 & 22 & 16.57 & 0.7866 & \\
\hline
\end{tabular}

ML: Maximum Likelihood

CLS: Conditional Least Square

ULS: Unconditional Least Square 
The 1st International Electronic Conference on Hydrological Cycle (CHyCle-2017), 12 -16 November 2017; Sciforum Electronic Conference Series, Vol. 1, 2017

Table 3. Goodness of fit statistic

\begin{tabular}{|c|c|c|c|}
\hline Parameter & ARIMA model & Estimation Method & Akaikc's Statistic \\
\hline \multirow{7}{*}{ 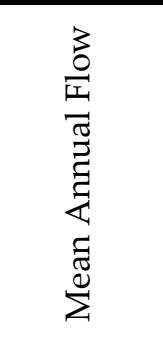 } & \multirow{3}{*}{$(1,1,0)$} & ML & 103.4247 \\
\hline & & CLS & 103.4469 \\
\hline & & ULS & 103.4316 \\
\hline & $(1,1,1)$ & CLS & 93.1350 \\
\hline & \multirow{3}{*}{$(4,1,1)$} & ML & 90.8381 \\
\hline & & $C L S$ & 88.8680 \\
\hline & & ULS & 91.0387 \\
\hline
\end{tabular}

Table 4. Forecasts from period 2006-7 to 2015-16 for mean annual inflow

\begin{tabular}{ccc}
\hline Period & Forecasted & Observed \\
\hline $2006-7$ & 139 & 135 \\
$2007-8$ & 133 & 131 \\
$2008-9$ & 131 & 128 \\
$2009-10$ & 131 & 130 \\
$2010-11$ & 127 & 125 \\
$2011-12$ & 132 & 127 \\
$2012-13$ & 132 & 131 \\
$2013-14$ & 134 & \\
$2014-15$ & 132 & \\
$2015-16$ & 132 & \\
\hline
\end{tabular}

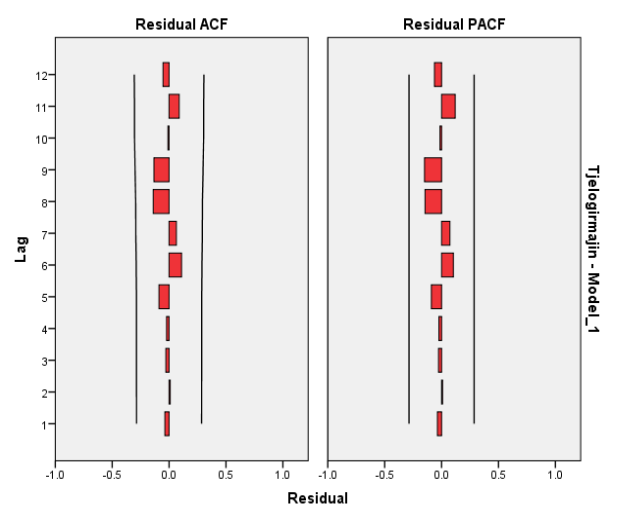

Figure 4. Autocorrelogram of residual series parameter

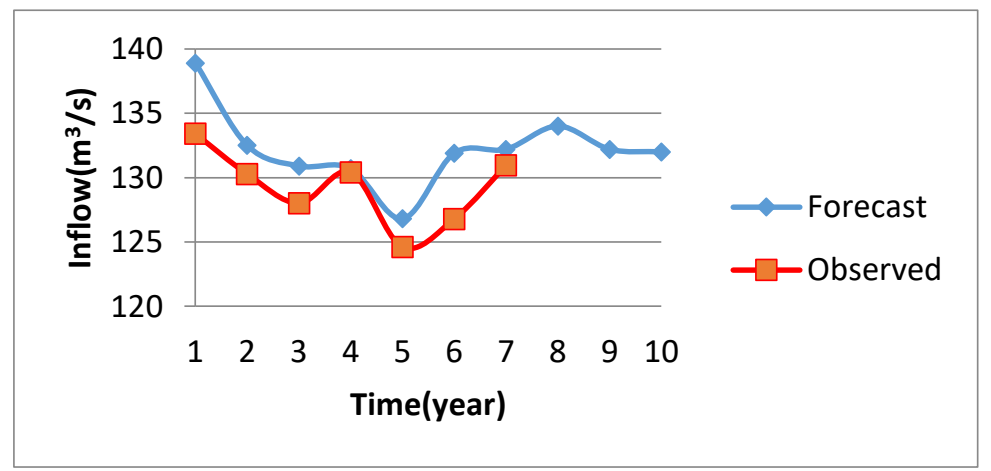


The 1st International Electronic Conference on Hydrological Cycle (CHyCle-2017), 12 -16 November 2017; Sciforum Electronic Conference Series, Vol. 1, 2017

Figure 5. Comparison of forecasted and observed annual inflow (2006-2015)

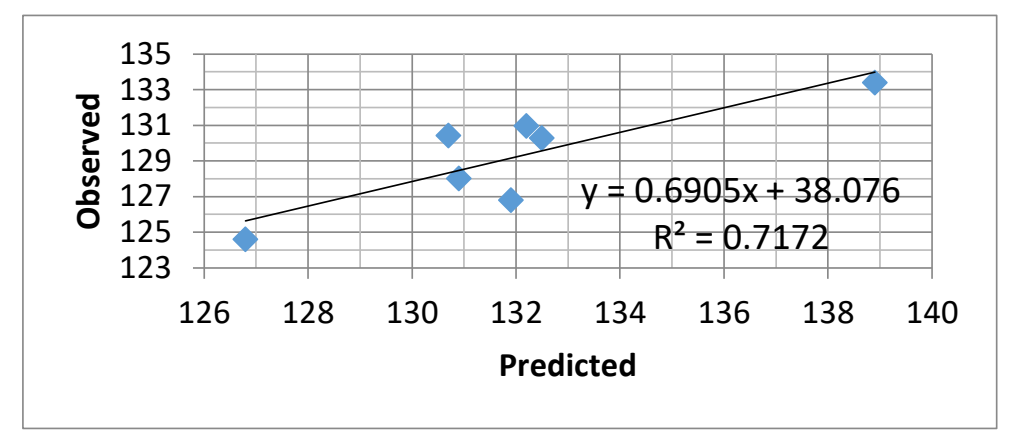

Figure 6. Correlation between actual values and predicted values of annual inflow to dam reservoir

\section{Conclusions}

Recognizing fluctuations of inflow during statistical period and predicting them are necessary for planning. Results from reviewing the annual average inflow with reviewing the diagrams indicated that:

- In order for predicting the studied parameters, there was used Box-Jenkins model and finally they assessed by providing final model. The correlation coefficient between predicted and observed annual inflow to Karkheh dam reservoir obtained about 0.72 . Therefore, considering the higher accuracy of model, it culd be used for anticipating the annual mean inflow.

- ARIMA $(4,1,1)$ model was the best model for annual average inflow to dam reservoir and it has lower Akaike vales than other models (AIC=88.89).

\section{References}

1. Adeli, A.; Fathi, M.; Moghadam; Musavi Jahromi, H. Using Stochastic Models to Produce Artificial Time Series and Inflow Prediction: A Case Study of Talog Dam Reservoir, Khuzestan Province, Iran. International Bulletin of Water Resources and Development, 2015, Issue 5.

2. Hamidi Machekposhti, K.; Sedghi, H.; Telvari, A.; Babazadeh, H. Forecasting by Stochastic Models to Inflow of Karkheh Dam at Iran. Civil Engineering Journal (C.E.J), 2017, Vol. 3, Issue 5.

3. Jalal Kamali, Navid Borhani, Alireza. Predicting the inflow to dam reservoir and need to use time series theory for operating the reservoir in drought conditions. First conference of hydraulic structures, 2001, pp. 77-84.

4. Musa, J.J. Stochastic Modelling of Shiroro River Stream flow Process, American Journal of Engineering Research (AJER), 2013, Vol. 2, No. 6, pp. 49-54.

5. Shakeel, A.M.; Idrees, A.M.; Naeem H.M.; Sarwar, B.M. Time Series Modelling of Annual Maximum Flow of River Indus at Sukkur, Pakistan Journal of Agricultural Sciences, 1993, Vol. 30, No. 1.

6. Srikanthan, R.; McMohan, T.A.; Irish J.L. Time series analysis of annual flows of Australian streams, Journal of Hydrology, 1983, Vol. 66, pp. 213-226.

7. Stojković, M.; Prohaska, S.; Plavšić, J. Stochastic structure of annual discharges of large European rivers, J. Hydrology and Hydromechanics, 2015, Vol. 63, No. 1, pp. 63-70.

8. Vijayakumar, N.; Vennila, S. A comparative analysis of forecasting reservoir inflow using ARMA model and Holt winters exponential smoothening technique, International Journal of Innovation in Science and Mathematics, 2016, Vol. 4, No. 2, pp. 85-90.

(C) 2017 by the authors; licensee MDPI, Basel, Switzerland. This article is an open access article distributed under the terms and conditions of the Creative Commons by Attribution (CC-BY) license (http://creativecommons.org/licenses/by/4.0/). 